\title{
Entre céu e terra, a bola. Uma introdução
}

\section{Carlos Nolasco e Francisco Pinheiro}

\section{(2) OpenEdition}

\section{Journals}

Edição electrónica

URL: http://journals.openedition.org/rccs/7281

DOI: $10.4000 /$ rccs.7281

ISSN: 2182-7435

\section{Editora}

Centro de Estudos Sociais da Universidade de Coimbra

Edição impressa

Data de publição: 1 setembro 2018

Paginação: 105-110

ISSN: 0254-1106

\section{Refêrencia eletrónica}

Carlos Nolasco e Francisco Pinheiro, «Entre céu e terra, a bola. Uma introdução », Revista Crítica de

Ciências Sociais [Online], 116 | 2018, posto online no dia 31 julho 2018, consultado o 24 setembro 2020. URL : http://journals.openedition.org/rccs/7281 ; DOI : https://doi.org/10.4000/rccs.7281 


\section{CARLOS NOLASCO, FRANCISCO PINHEIRO}

\section{Entre céu e terra, a bola. Uma introdução}

O poeta brasileiro Carlos Drummond de Andrade utilizou precisamente este título que agora recuperámos para refletir sobre a existência de "dois céus paralelos" (2014: 120): o principal, aquele que está "nas alturas", e o segundo, o que resulta do futebol e dos "santos" por ele criados. É precisamente este valor de divindade-religiosidade, obviamente simbólico, que o futebol assumiu desde o seu surgimento.

Criado no século XIX, consolidado e globalizado no século seguinte e totalmente mercantilizado no novo milénio, o futebol tornou-se uma espécie de inevitabilidade na vida contemporânea. Não está somente nos estádios, como em todos os espaços de sociabilização, existindo como uma futebolização (muitas das vezes fascizante do discurso popular e mediático) da sociedade globalizada, sendo ele mesmo um dos mais marcantes fenómenos da própria globalização. É tema comum de conversas, obsessão para muitos, assunto dominante na comunicação social, invade o espaço público e o campo político, assume-se como entidade cotada em bolsa, produto transacionado em múltiplos mercados. Afirmar a importância do futebol nas sociedades contemporâneas tornou-se uma evidência exaustiva, desde logo pela posição hegemónica que o jogo ocupa no âmbito da cultura popular massificada, mas também pelo caráter transcendente que tem no quotidiano das pessoas e das sociedades. Tudo isto não é exclusivo de um único país ou de um grupo restrito de países, e, ainda que com intensidades variáveis, estende-se à escala global, deixando poucos espaços fora da sua dinâmica e lógica competitiva. Tornou-se, assim, no outro "céu", na assunção de Drummond.

Intrinsecamente, o futebol é um jogo simples. Disputado por duas equipas, com idêntico (ou aproximado) número de jogadores, os quais utilizando predominantemente os pés, por vezes a cabeça e excecionalmente as mãos (por um dos elementos do jogo, o guarda-redes), têm como objetivo introduzir uma bola na baliza da equipa adversária, ganhando quem mais vezes o fizer. $\mathrm{Na}$ informalidade da rua, nos terrenos baldios da periferia de qualquer cidade, em pavilhões ou nos estádios, o futebol joga-se sempre da mesma forma: fintas, passes, remates 
e golos são a sua substância. Consoante o espaço em que é jogado, o perfil dos jogadores e as regras estabelecidas, as variantes futebolísticas sucedem-se num contínuo que vai da informalidade do futebol de rua ao profissionalismo da alta competição, onde o modelo institucional da Fédération Internationale de Football Association (FIFA) se constitui como hegemónica.

Inserido na dinâmica de industrialização, urbanização e modernidade da Inglaterra de meados do século XIX, ao jogo lúdico de futebol foram adicionados um conjunto de elementos que o converteram em desporto: a institucionalização, com a criação de entidades federativas que a nível nacional e internacional se encarregaram de uniformizar regras e organizar competições; a racionalização do jogo, no sentido da rentabilização de desempenhos técnicos e táticos, com vista a potenciar a competitividade; a secularização das práticas, descoladas do misticismo religioso e cada vez mais associadas às dinâmicas da modernidade. Ao futebol, entretanto convertido em desporto, foram-se juntando outras camadas culturais e simbólicas, identitárias, políticas e económicas ao longo do século Xx. Neste processo, o futebol, apesar das sucessivas metamorfoses que converteram os clubes em empresas, os jogadores em trabalhadores e os adeptos em consumidores, continua a ser um jogo. À imagem e semelhança do que as crianças fazem em qualquer jogo na rua, os jogadores dos mais importantes clubes fazem exatamente o mesmo, jogam. Essa persistência do espaço mágico do jogo no domínio do sofisticadíssimo futebol contemporâneo converte esta modalidade desportiva numa atividade peculiar, facto que se reflete na existência de um espaço/tempo paralelo ao espaço/tempo real, legitimando práticas associais transgressivas da normalidade.

Sendo um jogo simples, o futebol é, contudo, um fenómeno complexo e contraditório pela multiplicidade de dimensões que acumula e pelas emoções que suscita. Segundo o antropólogo Christian Bromberger (1998), o futebol é uma metáfora da vida e, por isso, "a mais séria bagatela do mundo". Ideia que se reflete nas palavras de Bill Shankly, antigo futebolista escocês e lendário treinador do Liverpool (1959-1974), quando afirmou que "o futebol não é uma questão de vida ou morte, é muito mais importante que isso". ${ }^{1}$ Também o realizador sérvio Emir Kusturica, quando inquirido sobre se a Jugoslávia de antes de 1990 era uma ficção, respondeu que "não se sente um país como uma ficção quando há uma seleção nacional de futebol". ${ }^{2}$ Essa constatação remete para a recriação das "comunidades imaginadas" (Anderson, 2006), das quais o Brasil é um exemplo, legitimado por Gilberto Freyre (1938), quando refere a especificidade do jeito

\footnotetext{
${ }^{1}$ Frase proferida durante uma entrevista, quando comentava a relação entre os adeptos do Liverpool e os do Everton. Consultado a 02.05.2018, em http://www.shankly.com/article/2517.

${ }^{2}$ Semanário português Já, de 14 de março de 1996.
} 
brasileiro de jogar, 3 e sublinhado por Nelson Rodrigues, quando afirma que a seleção brasileira "é a pátria em calções e chuteiras, a dar rútilas botinadas, em todas as direções. O escrete representa os nossos defeitos e nossas virtudes" (1994: 179). ${ }^{4}$ Constatamos assim que o futebol, sendo um jogo simples, não é um fenómeno unidimensional e linear. Bem pelo contrário, é um fenómeno complexo e contraditório, condensando em si uma multiplicidade de dimensões latentes (Elias e Dunning, 1992: 49), sistematicamente encobertas pela exaltação dos resultados das competições e pelas narrativas apologéticas dos "grandes" jogos e jogadores. O futebol assume-se como "uma linguagem", com "os seus poetas e os seus prosadores", como sublinhou o realizador italiano Pier Paolo Pasolini (2015:54).

Paradoxalmente, o futebol tem concentrado pouca atenção e consideração por parte das Ciências Sociais e Humanas, sobretudo no contexto do sul da Europa. Somente nas últimas duas décadas essa situação evoluiu favoravelmente para um maior volume de produção académica, assistindo-se a uma progressiva institucionalização do tema em disciplinas como a História, a Sociologia, a Antropologia ou a Economia. Contudo, este continua a ser um fenómeno social displicentemente considerado e desprezado por um certo mainstream académico. A desconsideração académica para com o futebol resulta em grande medida de um preconceito epistemológico, que é comum a muitos outros fenómenos expressivos da cultura popular. Esse desprezo pelo futebol deve-se ao facto de ser considerado como algo "que se avalia de modo negativo no complexo dicotómico de sobreposição convencionalmente aceite, como, por exemplo entre fenómenos de trabalho/ /azer, espírito/corpo, sociedade/prazer, económico/não económico [...] ou seja, segundo o pensamento reducionista e dualista ocidental, o desporto é entendido como coisa vulgar, uma atividade de lazer orientada para o prazer, que envolve o corpo mais do que a mente, e sem valor económico", como afirmaram os sociólogos Norbert Elias e Eric Dunning em 1992 - reflexão que ainda hoje se mantém atual. O facto de o futebol ser cada vez mais um produto económico tem contribuído para atenuar esse preconceito, contudo, o mesmo não é totalmente superado devido à inevitável componente irracional sempre inerente ao jogo.

O desprezo académico para com o futebol resulta de um entendimento crítico de que o desporto que funciona como escape para as tensões do quotidiano é o mesmo que prepara os indivíduos para mais trabalho, realçando-se assim o potencial de alienação que o futebol contém, bem como o seu caráter funcional na reprodução do sistema capitalista (Brohm e Perelman, 2006). Ainda que não de forma direta para com o futebol, o desprezo de autores como

\footnotetext{
3 Segundo Freyre, o estilo brasileiro de jogar - "o qual arredonda e adoça o jogo inventado pelos ingleses" - define-se com base nas qualidades da surpresa, manha, astúcia, ligeireza e espontaneidade individual.

${ }^{4}$ Texto inicialmente publicado sob a forma de crónica, em 2 de junho de 1976 no jornal O Globo.
} 
Theodor Adorno (2003) pelas manifestações massificadas enquanto expressão da cultura industrial, ou de Hannah Arendt (2006) para com as massas humanas sem vínculo social a qualquer projeto político, provocaram uma preconceituosa negação do valor social do futebol enquanto objeto de investigação.

O olhar displicente sobre o futebol contribuiu para a ausência de uma interpretação crítica, que fosse além da crítica marxista. Simultaneamente, o olhar acrítico sobre este desporto alimentou uma interpretação estruturalista do mesmo, na qual se realçam essencialmente os méritos funcionais da simbiose entre futebol e sociedade. Contudo, reflexo das circunstâncias em que acontece, o futebol contemporâneo, e em particular o futebol formal de competição, metamorfoseou-se com a economia, adulterou-se com a política e frustrou-se com a corrupção, violência, xenofobia e discriminação, para além de prática pós-colonialista, instrumento de totalitarismos e jogo de estratégia capitalista. Todas estas circunstâncias tornam urgente um olhar que questione a forma do futebol acontecer, as suas possibilidades e potencialidades, ou então a ausência das mesmas. Num momento de questionamento das sociedades atuais, em que se colocam perguntas fortes ao modelo político e económico dominante e ao paradigma epistemológico que o sustenta, o futebol enquanto produto desse contexto não pode deixar de ser questionado.

Os textos que se apresentam neste dossier vão ao encontro precisamente desta preocupação, simultaneamente científica e social, mostrando que as manifestações fascistas, nacionalistas e xenófobas nas bancadas dos estádios, bem como os processos de corrupção que corroem as instâncias futebolísticas e a apropriação económica e financeira dos clubes, são produto e consequência de sociedades que se deslumbram com o jogo. Possibilidades alternativas existem, como o modelo de fútbol callejero proposto num dos textos. Assim, este dossier é composto por quatro artigos, diversos na sua origem geográfica e autoral, e distintos na abordagem que desenvolvem.

O artigo de Simon Martin, "Football, Fascism and Fandom in Modern Italy" aborda a persistência de manifestações e comportamentos fascistas nos estádios de futebol italianos. Com base numa análise que remonta à década de 1920 até ao presente, o autor estabelece uma relação entre o desenvolvimento do futebol em Itália e a evolução do Estado, fazendo um paralelo com a continuidade de manifestações fascistas nos estádios. Assumindo a não linearidade da história, Simon Martin assinala a intervenção do Estado fascista dos anos 20 e 30 no futebol, nomeadamente na forma como utilizou a modalidade para se afirmar interna e internacionalmente. As atuais manifestações fascistas nas bancadas dos estádios, sendo uma reminiscência desse período, devem-se, segundo o autor, à abstenção do Estado em intervir no assunto. $\mathrm{O}$ artigo ganha particular relevância quando se constata a sistemática utilização que, por toda a Europa, 
movimentos de extrema-direita fazem dos estádios, como locais privilegiados para propagandearem mensagens nacionalistas e xenófobas, exercerem violência e recrutarem novos membros entre as claques radicais dos clubes.

No texto "Fútbol, modelos jurídicos y mercado: el dilema de los clubes en Sudamérica", Verónica Moreira analisa os impactos da mudança estrutural do futebol sul-americano em consequência do processo de mercantilização global do jogo. Centrado no caso argentino, mas tendo igualmente em consideração outras realidades, nomeadamente os casos do futebol chileno e brasileiro, a autora estabelece um vínculo entre a forma como as mudanças de perfil jurídico dos clubes para sociedades anónimas desportivas se refletem no envolvimento dos adeptos, nas dinâmicas dos mercados futebolísticos e nas políticas institucionais. O tema abordado por Verónica Moreira é de enorme pertinência e transportável para a própria realidade europeia, pois a reformulação jurídica das entidades desportivas para um modelo empresarial revela inúmeras incompatibilidades com o envolvimento emocional dos adeptos na gestão dos clubes. Por outro lado, esse modelo é contrário a uma gestão emocionada das entidades desportivas para com um mercado racionalizado e competitivo. À semelhança do que se passou na Europa, em particular no futebol britânico, o descontentamento dos adeptos face às transformações estruturais e decisões políticas tomadas pelos dirigentes dos clubes está a provocar pontos de tensão num equilíbrio já de si precário.

O artigo de Maurício Mendes Belmonte e Luiz Gonçalves Junior, intitulado "Fútbol callejero: nascido e criado no Sul", propõe analisar como uma prática futebolística alternativa ao futebol oficial da FIFA se constitui como socialmente emancipatória. O fútbol callejero surge como um jogo de rua, não submisso ao modelo de futebol dominante, com outra lógica de ser jogado e com objetivos distintos da vitória. Essa outra filosofia de jogo proporciona aprendizagens mútuas de consciência social, de cidadania e emancipação, desde logo porque nunca se joga contra alguém mas sim com alguém. O texto, para além de caracterizar este fútbol callejero, mostra como a prática alternativa deste jogo se constituiu como projeto educativo de uma motricidade relevante, nascida e criada no Sul. Considerando o suposto esgotamento do modelo formal de futebol, importa procurar alternativas de jogo que superem as formas de dominação capitalista, patriarcal e racial da modernidade. Este artigo vai ao encontro dessas alternativas, respondendo a muitos dos desafios das epistemologias do Sul.

A fechar este dossier apresentamos uma reflexão do investigador James M. Dorsey, um dos mais respeitados especialistas sobre futebol no Médio Oriente. É uma das vozes mais ativas e controversas na análise sobre o fenómeno futebolístico nessa região, fazendo neste artigo uma reflexão sobre as implicações políticas da organização do Campeonato do Mundo de Futebol de 2022 pelo Catar. Envolvido numa permanente crise diplomática e em boicotes sucessivos por parte 
da Arábia Saudita, Emirados Árabes Unidos, Egito e Bahrain, o pequeno estado do Catar definiu como prioritária uma estratégia soft power, tendo o desporto, em especial o futebol, como elemento-chave. Questões religiosas, corrupção, diplomacia e o papel político da FIFA são elementos que se entrecruzam neste texto, que deve ser visto como um ensaio reflexivo, baseado numa profunda pesquisa nos media e que tem como principal foco o futebol e a política na região do Golfo Pérsico. Para Dorsey, "desporto é política, por definição".

Este dossier é assim formado por textos complementares entre si, abrangendo temáticas e abordagens diferentes, sobre três regiões distintas do globo. O ponto de convergência é "a bola", um dos "dois céus paralelos" de que falava Carlos Drummond de Andrade.

\section{Referências bibliográficas}

Adorno, Theodor W. (2003), Sobre a indústria da cultura. Coimbra: Angelus Novus.

Anderson, Benedict (2006), Imagined Communities. London: Verso.

Andrade, Carlos Drummond de (2014), Quando é dia de futebol. São Paulo: Companhia das Letras.

Arendt, Hanna (2006), As origens do totalitarismo. Lisboa: Dom Quixote.

Brohm, Jean-Marie; Perelman, Marc (2006), Le football, une peste émotionnelle. Paris: Éditions Gallimard.

Bromberger, Christian (1998), Football, la bagatelle la plus sérieuse du monde. Paris: Bayard Centurion.

Elias, Norbert; Dunning, Eric (1992), A busca da excitação. Lisboa: Difel.

Freyre, Gilberto (1938), "Foot-ball mulato", Diário Pernanbucano, de 17 de junho.

Pasolini, Pier Paolo (2015), Sobre el deporte. Barcelona: Contra.

Rodrigues, Nelson (1994), A pátria em chuteiras. São Paulo: Companhia das Letras.

\section{Carlos Nolasco}

Centro de Estudos Sociais da Universidade de Coimbra

Colégio de S. Jerónimo, Largo D. Dinis, Apartado 3087, 3000-995 Coimbra, Portugal

Contacto: cmsnolasco@ces.uc.pt

\section{Francisco Pinheiro}

Centro de Estudos Interdisciplinares do Século XX da Universidade de Coimbra - CEIS20

Rua Filipe Simões, 33, 3000-186 Coimbra, Portugal

Contacto: franciscopinheiro72@gmail.com 